\title{
The follow-up control of the body sequencing process at the paint shop
}

\author{
JOLANTA KRYSTEK \\ SARA BYSKO
}

Dr inż. Jolanta Krystek, jolanta.krystek@polsl.pl, https://orcid.org/0000-0003-2015-3453 - Politechnika Śląska, Gliwice, Polska

Dr inż. Sara Bysko, sara.bysko@polsl.pl, https://orcid.org/0000-0003-4065-8213 - Politechnika Śląska, Gliwice, Polska

A modified method of follow-up production control that can be used in a multi-version car body sequencing process at the paint shop department is presented. The actual structure of the paint shop along with the buffer was subjected to tests (Car Sequencing Problem 4.0). The main goals of the research were to minimize the number of changeovers resulting from color changes and to synchronize these changeovers with forced, periodic cleaning of paint guns.

KEYWORDS: automotive industry, follow-up production control, Car Sequencing Problem 4.0, follow-up sequencing algorithm, changeovers

\section{Introduction}

High market requirements, ensuring timely delivery of orders, the need to respond quickly to the needs of a particular customer, and minimizing the costs of production, storage and transport, force producers to use a flexible form of production organization. It is characteristic of a multi-version, repetitive production to order (Make to Order, MTO), and its effectiveness is ensured by sequencing (mixing) product variants as part of the same process.

An example of such production is a multi-stage car production process [1,2]. Each stage has its own set of restrictions and requirements that must be met when determining the order, in which cars are manufactured. This means that if the car sequence is not planned correctly, the workstations of the individual departments may be overloaded. The result is frequent device retooling. At the same time, high process efficiency is required, which can be maintained by placing buffers to ensure continuity of production.

The buffer control system located in the paint shop department should enable the solution of two problems directly associated with the buffer function, i.e.

- management and control of the continuous flow of cars,

- automatic generation - optimal in terms of given criteria - car sequences.

Optimization of the paint line performance is carried out by sequencing the body in terms of their color variants. Sequences determine the number of refinish varnish nozzles - the more color changes, the higher the production costs. The reason for this is not only the consumption of solvent used to clean the nozzle when changing color, but also the loss of unused paint, that remains on the nozzle walls during the changeover [1].

Another challenge is to automate executive decision making. Unfortunately, the control of such buffers is still carried out by the operator and decisions are made based on his experience.

The paper presents the follow-up sequencing algorithm (FuSA) of the body sequencing process (production variants) in a multi-version, repetitive painting process based on the idea of a follow-up production control (NSP).

The role of the FuSA algorithm is to generate bodywork sequences targeted for painting that will minimize the number of changes due to color change and synchronize them with periodic cleaning of the paint nozzles. The comparative research also used original priority and theory-based algorithms [7]. 


\section{Follow-up track of the body sequencing process}

The follow-up sequencing algorithm is designed for the current generation of executive plans - body sequences. Decisions are made for a horizon equal to or shorter than the periodic cleaning period (NPerClean). Implementation plans keep pace with operational plans from the system coordination unit. Decisions of the FuSA algorithm are made on the basis of the algorithm state, which consists of recent decisions and status of backlogs in the implementation of operational plans by implementing plans [10].

The FuSA algorithm integrates two algorithms. The first of them, the loading algorithm, is designed to determine the transport line, on which the body located on the loading conveyor is to be loaded to create a color block. The unloading algorithm generates a current execution plan understood as a set of decisions defining the order of buffer unloading in a time horizon equal to or shorter than NPerClean. In general case, this decision concerns body set, therefore it is also necessary to specify, in which order, the individual bodies from this set should leave the buffer. This approach ensures that the decisions made are the best from the perspective of a current situation on the line, but at the same time, the possibility of their improvement in the planning horizon of NPerClean length is not excluded, as shown in figs. 1 and 2.

\section{Case 1}

Assuming that the interval of periodic cleaning is NPerClean $=7$, based on the analysis of the buffer status (fig. 1), it can be concluded that it is impossible to generate the optimal (single-color) subsection for the planning horizon with NPerClean length, therefore body sets with the color feature forming uniform blocks, are searched.

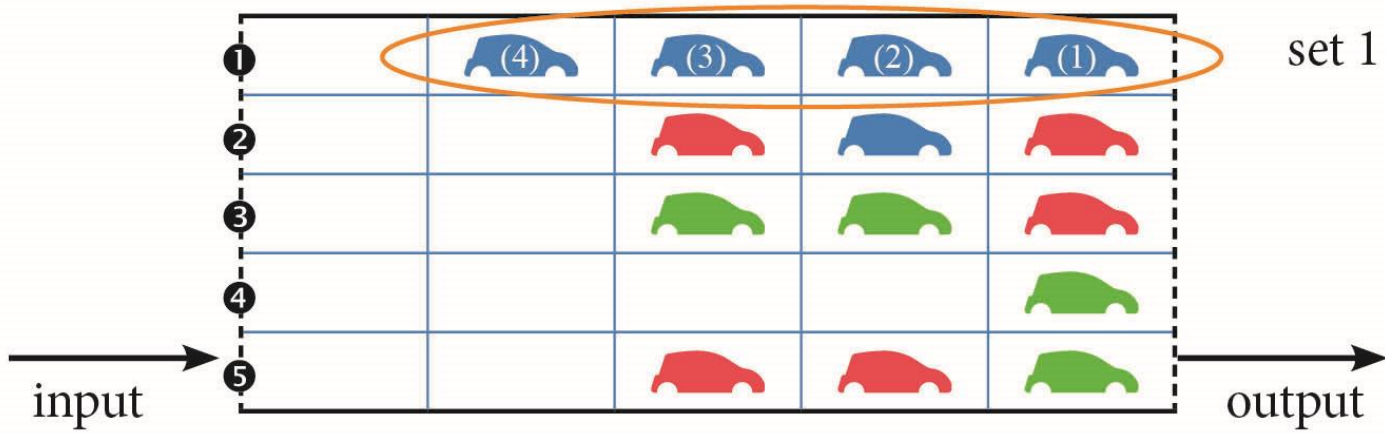

Fig. 1. Initial buffer state for an example of block determination for a planning horizon shorter than NPerClean $=7$

A set of four blue bodies from the first transport line (set 1) may be directed to the painting cell; individual car bodies from the set will be unloaded in the order according to the FIFO rule, i.e.: (1), (2), (3), (4). In this way, an executive plan with a planning horizon of 4 is obtained. The next output decision is taken when the buffer leaves the last car body from the set designated in previous decision. When subsequent car bodies from set 1 leave the buffer, car bodies appear at its entry, for which input decisions must be made. If blue bodywork appear at the entry, they are directed to the transport line, on which bodywork in this color was located directly in front of them. If car bodies of a different color appear at the entry, they are directed to the lines in accordance with the adopted criteria. Based on the analysis of the current buffer status, the algorithm decides to send a set of three blue bodies from the first transport line to the exit (set 2).

Situation presented in fig. 2 confirms that taking the first decision, for which the length of the implementation plan is shorter than NPerClean (four car bodies out of seven required - set 1 ), did not exclude the possibility of generating the optimal sub-sequence in the planning horizon with the length of NPerClean.

Case 2

An important feature of the FuSA algorithm is the presence of an information coupling between the loading and unloading algorithms (figs. 3 and 4).

Decisions taken are aimed at optimizing both indicators determining the quality of the output sequence and buffer status. The algorithm analyzes the effects that the decision of the car body entering the buffer will have on the situation at its exit, and - similarly - decisions of the exit of the buffer are made taking into account the initial situation. Since the optimal sub-sequence cannot be determined on the basis of the buffer status with a 
planning horizon of NPerClean $=7$, the output algorithm will direct a set of six blue bodies on the first and fifth transport lines to the paint cell. Information about the decision will be forwarded to the input algorithm. At the same time, the input algorithm will announce that the entry has a blue body that can be used to create the optimal NPerClean-element sub-sequence, but then, it is necessary to free up the space on the first transport line. First, the body from the first transport line will be directed to the painting cell, and this information will be given to the input algorithm.

The FuSA algorithm decision regarding buffer input is made taking into account information about both the body on the loading conveyor and bodies on preceding positions (fig. 4). For example, the algorithm will not direct the blue body to the fourth transport line, because such a decision would block the possibility of placing the body in orange and lengthening the block in that color.

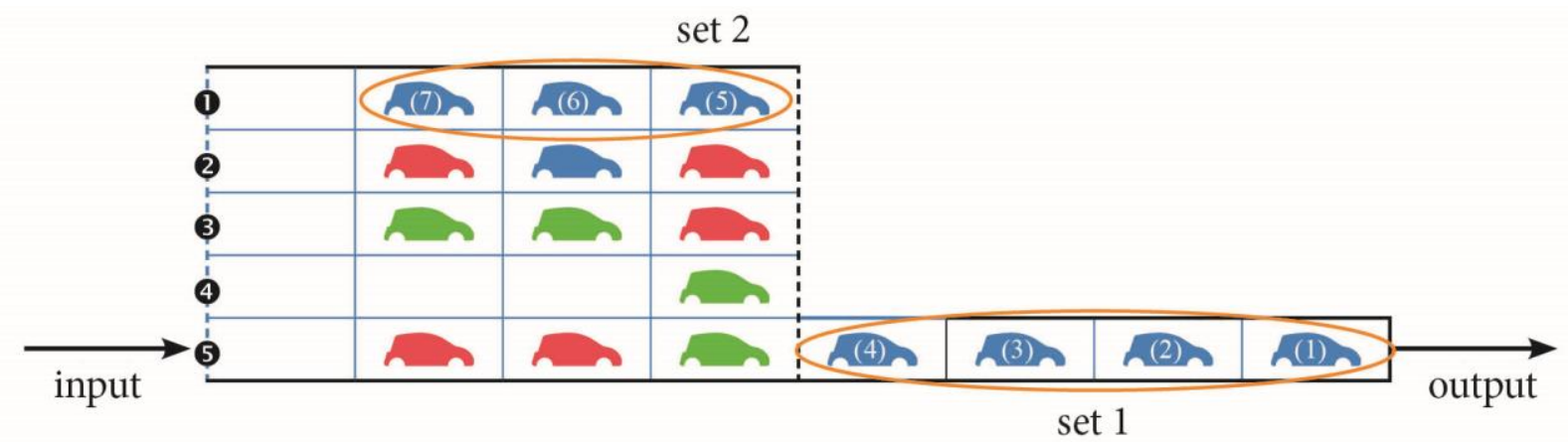

Fig. 2. Buffer status for an example of determining the complement of the optimal NPerClean-element sub-sequence

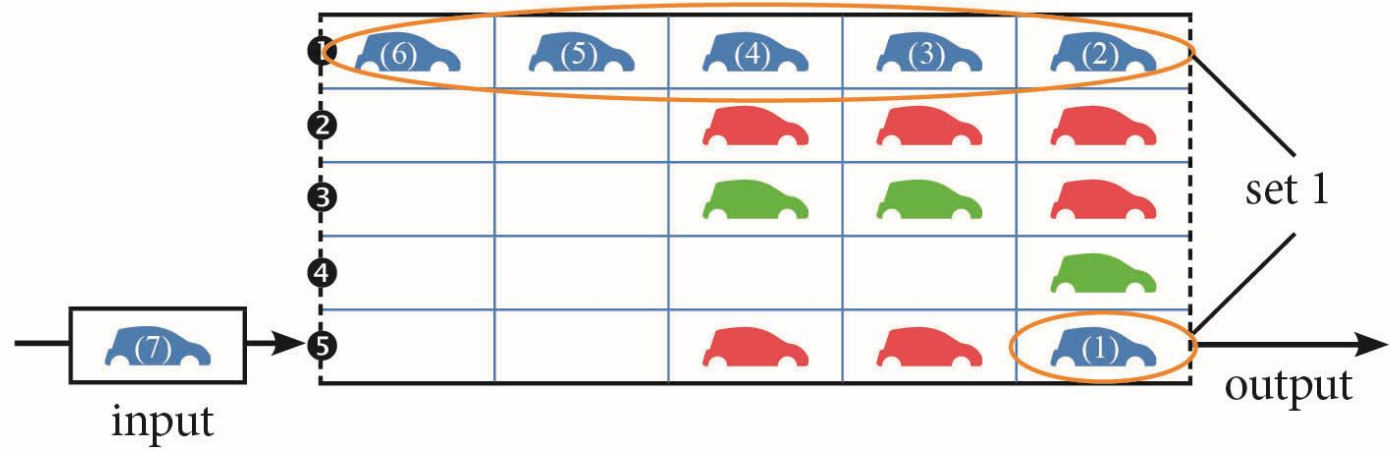

Fig. 3. Initial buffer state for an example of using information coupling of the FuSA algorithm

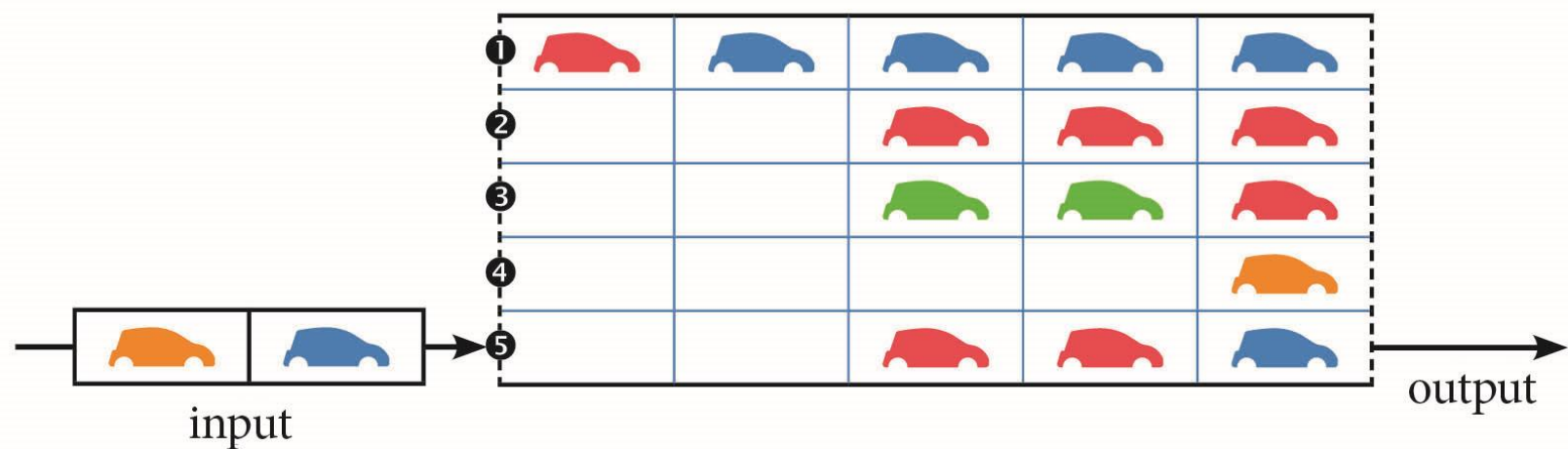

Fig. 4. Buffer status for decision making taking into account the color of the car body located at the buffer input

Case 3

An important feature of the FuSA algorithm is that it has the property of keeping up with a changing production plan. A production plan is created for a limited time horizon (usually 3-4 hours) and is not adjusted on a regular basis with a known period. After each correction of the plan, the number of the car body 
in a specific color changes. Color priorities are updated after each decision to leave the car body from the buffer. The PrioFuSA ( $C X)$ color priority is determined by the formula:

$$
\operatorname{Prio}(c X)=\frac{N P P(c X)-N P(c X)-N B(c X)}{N P P}
$$

where:

- $N P P$ - number of cars in the Production Plan,

- $N P P(c X)$ - number of cars in $c X$ in the Production Plan,

- $N P(c X)$ - number of Produced cars in $c X$,

- $\quad N B(c X)$ - number of cars in $c X$ in the Buffer.

Example: at some stage of production, the following color priorities (PrioFuSA) were set based on the production plan: red $=7 / 10$, blue $=0$, green $=1 / 10$, orange $=0$, black $=5 / 10$, gray $=1$, pink $=9 / 10$.

The NPerClean value is 7.

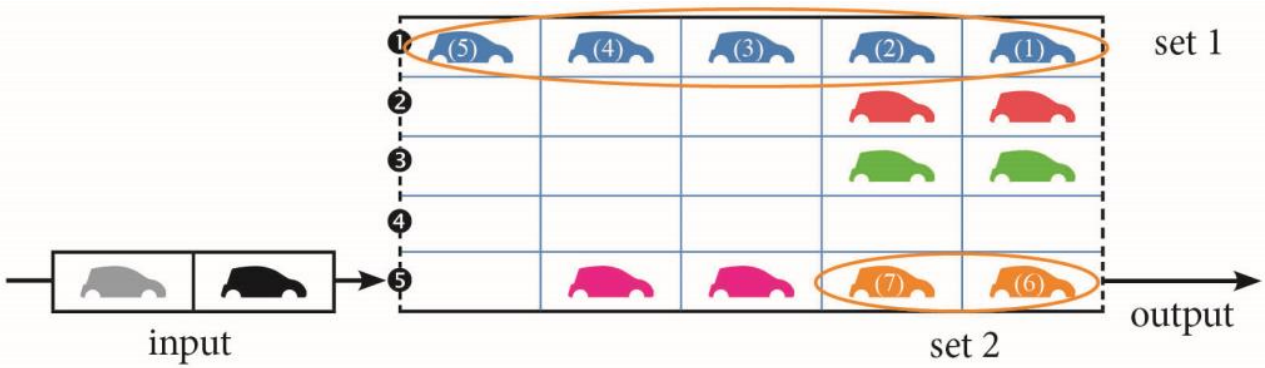

Fig. 5. Initial buffer status for decision making taking into account color priorities

Based on the priority analysis, it can be concluded that no more blue and orange body will appear at the buffer input. Therefore, it is reasonable to create a NPerCleanelement subsection from the body in these colors (set 1 and set 2 ) and direct it to the painting cell, which means freeing the first transport line. At the same time, the algorithm will have to decide which car body at the buffer input (black or gray) should be directed to the free line. Comparing the priorities of these colors: Prio (gray) > Prio (black), the first line will be designated for the body with a higher priority, i.e. gray, and it will be a free line (line 4). In this situation, the black body can be directed to the second, third or fifth line. Green has the lowest priority, therefore the black body will be directed to the third line.

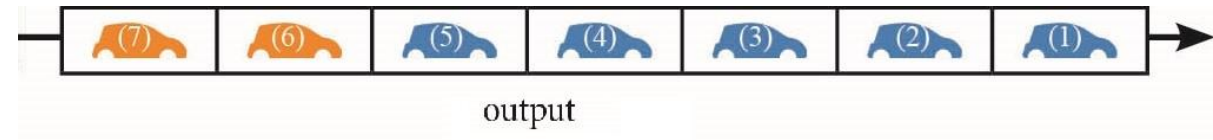

Fig. 6. Output sequence after considering the color priorities

The FuSA algorithm is also characterized by the fact that not only information from the current moment is taken into account when making decisions, but also the state of the buffer and its future situation, i.e. after the implementation of the execution plan. In other words, the algorithm concludes about the future buffer state and exit situation to adjust its operation in advance before real changes occur. This indicates the predictive nature of the algorithm.

\section{Summary}

Sequencing of cars to be painted is economically justified. The research concerned body sequencing at the paint shop department, including the presence of a buffer of finite capacity and defined structure on the production line. The main problem associated with the development of the sequencing method was to ensure its operation based on limited current information and a short time horizon, for which the production plan was known.

The process of making decisions related to designation of the transport line for the car body entering the buffer and choice of the car body transported to the paint station must be integrated, and decisions should be made in a real time. In addition, it was necessary to include both the changeovers of the paint nozzles, resulting from changes in paint colors, as well as periodic cleaning of the nozzle, ensuring good varnish quality, in the optimization criteria. 
A review of the literature showed the existence of a research gap in the field of effective body sequencing during painting process. As a result, a new concept for solving this problem was developed - Car Sequencing Problem 4.0 - which takes into account the actual structure of the paint shop and buffers used there; a buffer modeling tool was created, and an automatic control system was developed.

The work was financed from the funds provided for 02/010/BK-18/0102 and 02/010/BKM-18/0136, vol. 1.

\section{REFERENCES}

[1] Krystek J., Alszer S. „Współczesne problemy sekwencjonowania samochodów na wydziale lakierni". Mechanik, 7 (2017): 527-529.

[2] Krystek J., Alszer S. „Nowoczesne aspekty problemu sekwencjonowania samochodów na wydziale montażu". Przegląd mechaniczny. 9 (2017): 23-25.

[3] Boysena N., Emde S., Hoeck M., Kauderer M. "A survey on part logistics in the automotive industry". European Journal of Operational Research. 242 (2015).

[4] Parello Bruce D., Kabat Waldo C., Wos Larry. 1986. "Job-shop scheduling using automated reasoning: a case study of the car sequencing problem". Journal of Automated Reasoning. 2, 1 (1986): 1-42.

[5] Perron L., Shaw P. "Combining forces to solve the car sequencing problem". J.C. Regin, M. Rueher. Proceedings of CP-AI-OR'2004. Berlin: Springer-Verlag. 2004: 225-239. DOI: 10.1007/978-3-54024664-0_16.

[6] Solnon C., Cung Van Dat, Nguyen A., Artigues C. "The car sequencing problem: overview of state-of-the-art methods and industrial case-study of the ROADEF'2005 Challenge problem". European Journal of Operational Research, 191, 3 (2008): 912-927.

[7] Bysko S. "Sekwencjonowanie w produkcji wielowersyjnej dla skończonej pojemności bufora". Gliwice. Rozprawa doktorska (niepublikowana). 2019.

[8] Bysko S., Krystek J. "Automotive Paint Shop 4.0". Computers \& Industrial Engineering. DOI: 10.1016/j.cie.2018.11.056. (in printing).

[9] Krystek J. „Nadążne sterowanie produkcją jako metoda sekwencjonowania wariantów produktów”. M. Karkula, J. Matuszek, B. Skołud. Wokół inżynierii produkcji. Wydawnictwa AGH, Kraków. (2017): 121-128.

[10] Bysko Sara, Krystek Jolanta. 2020. "Follow-Up Sequencing Algorithm for Car Sequencing Problem 4.0". Szewczyk R., Zieliński C., Kaliczyńska M. (eds.) Automation 2019. Advances in Intelligent Systems and Computing. Springer. 920 (2020). 